\title{
Volumetric losses of the compression process in a hypocycloidal pump in the light of the gas desorption effect
}

ARTICLE INFO

Received: 27 July 2021

Revised: 3 August 2021

Accepted: 15 August 2021

Available online: 16 August 2021
The effect of gas desorption from the solution with nucleation of gas bubbles is a process that allows to improve fuel atomization in diesel engines. The advantage of such a process, which has been experimentally proven, is a significant reduction in harmful emissions. The conducted research highlighted one of the fundamental problems. This problem concerned the injection pump - it was necessary to design a new construction that would be adapted to the desorption effect. The authors of the work proposed a construction based on a hypocycloidal drive. Due to the nature of the process, i.e. the use of exhaust gases dissolved in diesel fuel, it was very important to analyze the volumetric losses of the compression process - this is the main goal of this article. The authors proved that for the adopted design assumptions, the power of volumetric losses resulting from compressibility is $0.25 \%$ of the power consumed by the pump.

Key words: gas desorption effect, hypocycloid, pump, injection system, volumetric losses

This is an open access article under the CC BY license (http://creativecommons.org/licenses/BY/4.0/)

\section{Desorption effect}

For many years, the development of diesel injection systems has been associated with the continuous increase of injection pressure $[5,16,18,1922,23,26]$. The authors of the study believe that the pursuit of higher and higher pressures and overcoming the related problems is not the only direction in the development of modern diesel injection systems. It has been proposed that the spraying process can be improved by introducing an additional physical factor into the process. This factor is related to the properties of the liquid-gas solution. This concept can be considered innovative as it is based on adding a certain amount of gas to the fuel. This gas is then dissolved in the fuel. This concept assumes, with the appropriate injection pressure, striving to achieve an equilibrium state. During the injection process, when a strong disturbance occurs, caused by the lifting of the needle in the sprayer, the process of releasing the gas dissolved in the fuel begins. This process was described as the effect of gas desorption from the solution with the nucleation of the gas bubbles - "desorption effect" for short. The main advantage of such a process, which has been experimentally proven, is a significant improvement in atomization compared to standard high pressure common rail injection systems. In addition, the injection pressure, which is also a significant advantage of the concept, is kept at a relatively low level, much lower than in modern common rail systems. This has an impact on the mechanical relief of the system components, and thus also its durability. This phenomenon can be compared to the opening of a bottle of sparkling water - the feature of such a solution when a pressure drop occurs is that the gas is released spontaneously from the entire volume of the liquid.

The determining factors for the occurrence and course of the dissolution process are temperature and appropriate pressure. Under normal atmospheric conditions, the influence of temperature is significant because the solubility of gases in liquids is greater at lower temperatures [10]. The second factor is particularly important as the gases are poorly soluble in liquids, so it is necessary to subject both fluids to high pressure. Given a constant temperature and the fact that a liquid is an incompressible liquid, the amount of gas that will dissolve in a given liquid is, in general, proportional to the pressure of the gas. It results from the Henry's law (1) valid for commonly used pressure values, assuming the Bunsen absorption coefficient for a given pressure.

$$
\mathrm{V}_{\mathrm{gas}}=\alpha_{\mathrm{V}} \cdot \mathrm{V}_{\mathrm{ol}} \cdot \mathrm{p}
$$

where: $\mathrm{V}_{\text {gas }}$ - volume of desorbed gas in oil, $\mathrm{V}_{\mathrm{ol}}$ - volume of oil, $p$ - pressure of oil, $\alpha_{V}-$ Bunsen's absorption factor.

It is the process pressure that influences the absorption coefficient - the higher it is, the higher the absorption (from def. the penetration of one substance (atoms) into a continuous-phase substance (gas, liquid)) - gas molecules is greater. Henry's law also shows the volume ratio of the phases, e.g. the ratio of the amount of dissolved air in the oil to the volume of the oil-air solution exceeds approx. 20 times, at the pressure $p=20 \mathrm{MPa}$ [6]. The equilibrium state is then achieved, under a specific momentary pressure. By increasing the pressure of the gas, the number of atoms penetrating the liquid also increases. On the other hand, when air particles dissolved in a liquid are in equilibrium with air particles above the liquid, it is then a full state of saturation. The state of equilibrium is the state of the equalized thermodynamic potential of the resulting solution and the gas phase. Such a state, in which all parameters remain constant, is achieved with constant pressure. It is possible to use the potential of the phenomenon when a negative pressure gradient occurs, i.e. when a fuel solution with gas is injected into the combustion chamber. The gas contained in the liquid is then released. This spontaneous process is the effect of lowering the thermodynamic potential with a sharp 
drop in the pressure of the solution, in which the implosion of air particles takes place [11].

The effect of gas desorption from the solution with the nucleation of the gas bubbles is shown in the Fig. 1.

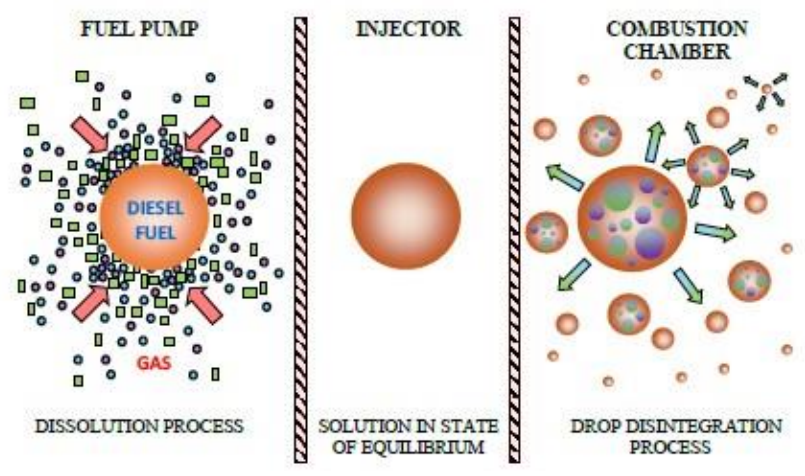

Fig. 1. The effect of gas desorption from the solution with the nucleation of the gas bubbles - illustration

The mechanism of gas release from the solution during an imbalance may occur in two ways. The reason is the speed of the expansion process, i.e. the size of the pressure difference of the state in which the equilibrium is maintained, and the lower assumed pressure. Thus, the greater the pressure difference, the more dynamic the process becomes [11-13]. The low speed of the process causes that the microbubbles that are formed, homogeneously distributed in the solution, expand and merge into the volume of the liquid. At a later stage, they are released to the volume occupied by the previously expanded gas. In contrast, in a dynamic process, the gas also expands in the volume of the liquid, but the microbubbles do not merge, creating tiny areas throughout the volume of the solution. The accompanying drop in pressure of the solution causes the gas in the bubbles to expand. This causes the bubbles to expand and create additional internal forces that act to break the liquid intermolecular bonds. The effect is to break the atomic bonds of adjacent particles, and thus the environment of the expanded gas. The effect of such a dynamic process is a noticeable turbulence of the entire volume. An illustrative example of such a phenomenon is the opening of a carbonated drink bottle and the release of $\mathrm{CO}_{2}$ from the saturated solution.

The assumptions of the concept provide for the use of engine exhaust gas that will be taken directly from the exhaust manifold. This approach has two advantages. The first is that the exhaust gases are readily available in the engine. The second important advantage is that the exhaust gas has a significant amount of $\mathrm{CO}_{2}$, which dissolves very well in liquids [2]. The research carried out so far at the Poznan University of Technology has proven the possibility of dissolving other gases in the fuel: air (oxygen) and CNG. Experiences gained during research and literature data [14] has shown that the most advantageous solution is to use carbon dioxide, which dissolves in liquids, and therefore also in diesel fuel, several dozen times better than, for example, air. Kozak and his team realized the theoretical basis and practical use of the desorption effect in combustion engines $[9,16,17]$. With the assumed injection pressure of
$35 \mathrm{MPa}$, the pressure increase rate was reduced by about $20 \%$ and the exhaust gas blackening was reduced by about $50 \%$. Moreover, the tests carried out showed a reduction of $\mathrm{CO}$ and $\mathrm{HC}$ emissions with a corresponding change in the movement of the charge in the combustion chamber by about $100 \%$, and $\mathrm{NO}_{\mathrm{x}}$ emissions by about $20 \%$.

The conducted research highlighted one of the fundamental problems. This problem was related to the injection pump - the desorption effect is not possible with pumps with camshafts. This is due to the fact that if the gas and fuel were to be brought to the delivery section of the pump during the suction stroke and the dissolving process in the fuel was carried out during compression, the high pressure pump would have to have radically different proportions compared to the existing pumps. The considerations and analyzes carried out in this area led to the need to create a new pump design with compact dimensions. On the basis of the tests performed, the authors proved that the optimal pressure of fuel injection with gas, at which the desorption effect occurs, is $60 \mathrm{MPa}$. It has been found that a positive displacement pump of the piston type should be used, which is essentially similar to conventional delivery sections, but with significantly different proportions due to the presence of gas. This analysis led to the concept of the hypocycloidal transmission.

\section{Hypocycloid drive}

The hypocycloid transmission (Fig. 2) consists of two wheels - the larger wheel (R) has interior toothing and the smaller wheel (r) has exterior toothing. Torque is applied to the smaller wheel, making it turn, however the larger wheel cannot rotate around its axis. The smaller wheel moves over the circumference of the larger wheel, and any point on the smaller wheel's radius moves in a curve called the hypocycloid. To create the working drive of the pump, a special case of a hypocycloid transmission with a gear radius ratio of $\mathrm{R} / \mathrm{r}=2$ was applied. This selection of gears makes it possible to achieve resultant linear motion.

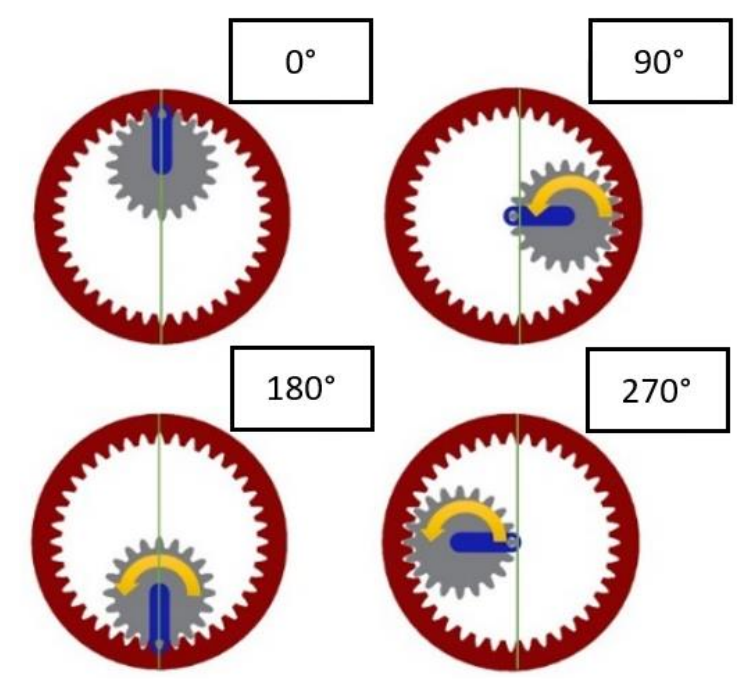

Fig. 2. Principle of operation of hypocycloid transmission

Using the above power transmission concept, the pump's design was created from the ground up. This solu- 
tion was patented. In this scope, several variants were prepared, with 1 to 4 delivery sections. This article presents the simplest of them, based on 1 delivery section (Fig. 3).

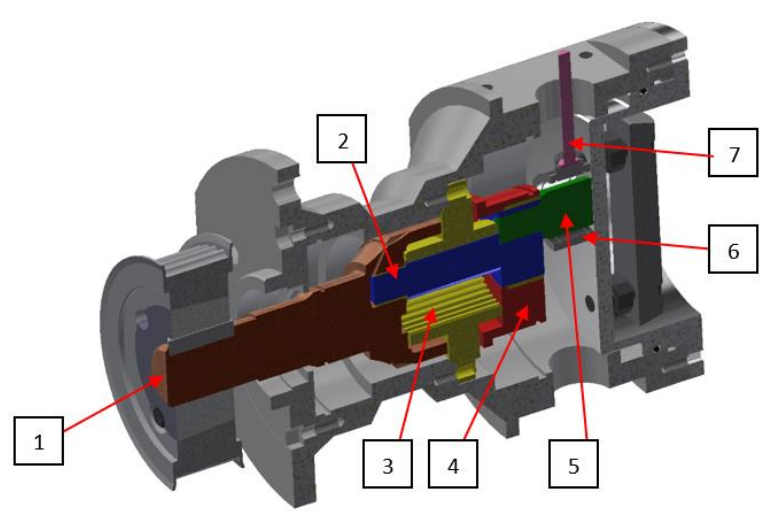

Fig. 3. Simplified model of hypocycloid pump presenting the most important components of the design: 1 - main shaft, 2 - countershaft, 3 toothed wheel, 4 - support, 5 - mandrel, 6 - mount, 7 - plunger

The innovative pump has a main shaft (1) to which power is transmitted. A countershaft (2) is mounted in the main shaft in such a manner that mutual rotation of both components is possible. A toothed wheel with exterior toothing is found on the countershaft and meshes with toothed wheel (3), which is immobile and fixed to the pump's body. Support (4) is a component that interacts with the countershaft from the side of the delivery section. Moreover, mandrel (5) is mounted eccentrically in the countershaft, interacting with mount (6) via a bearing. The plunger (7) and its guiding element, situated so that it can slide within the cylinder of the delivery section, is fixed to this mount. Both the main shaft, support and mandrel have bearings (accordingly, (8-10) - Fig. 4).

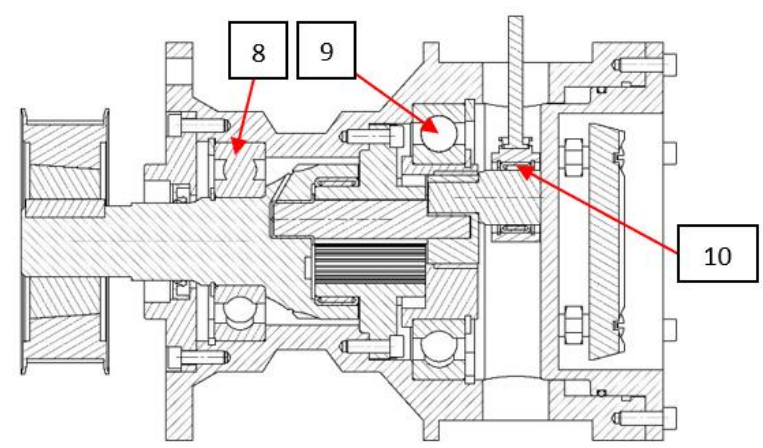

Fig. 4. Hypocycloidal drive pump - cross section with marked bearings

The use of the desorption effect determined the design of an atypical delivery section (Fig. 5). The main components of the section are the cylinder and body. The piston's downward motion generates underpressure, which displaces the ball and spring in the one-way gas valve. At this point, the space above the piston is filled with gas that is sucked in. Further downward movement of the piston uncovers the channel feeding pressurized fuel, which is mixed with the gas contained in the cylinder, simultaneously causing its preliminary compression. The section is filled, which increases pressure and closes the gas valve. Upward motion of the piston closes the fuel feed channel and compresses the mixture further, and during this time, the gas dissolves in the fuel until an equilibrium solution is obtained. Complete dissolution of gas in Diesel oil is possible thanks to the large stroke of the hypocycloid pump. After the initial pressing force on the spring in the one-way outlet valve is surmounted, the solution is pumped into the high-pressure line and then into the fuel rail.

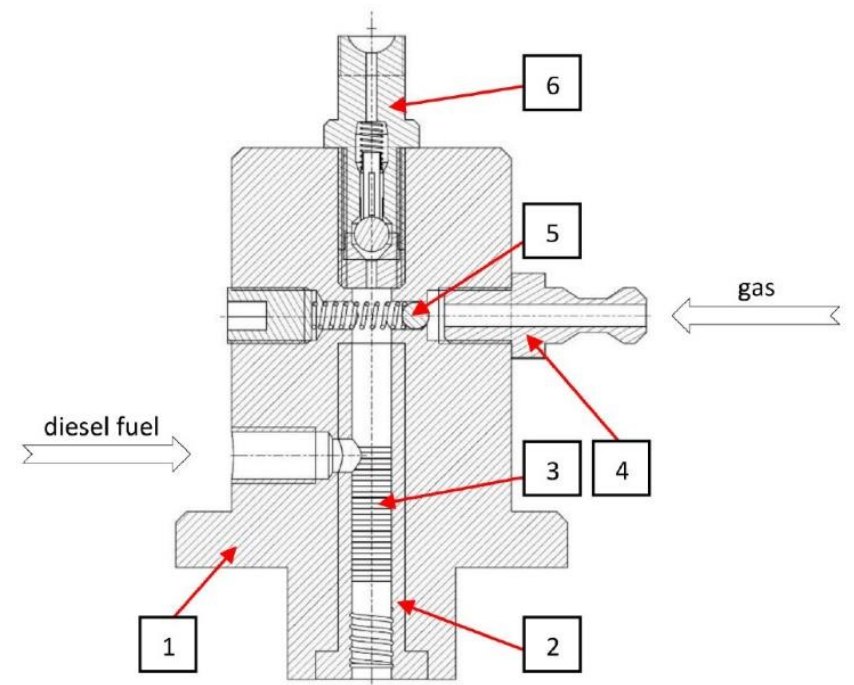

Fig. 5. Delivery section of hypocycloid pump: 1 - body of delivery section, 2 - cylinder, 3 - section labyrinth seal, 4 - gas stub pipe, 5 - oneway gas valve, 6 - one-way outlet valve

An important aspect when designing the pump was to determine the dimensions of the delivery sections in which the dissolution of exhaust gases in diesel fuel takes place. For this purpose, it is crucial to determine the bulk modulus and the coefficient of solubility of the solution of diesel fuel and exhaust gas [24].

\section{The bulk modulus and the coefficient of solubili- ty of the solution of diesel fuel and exhaust gas}

In order to properly design the delivery section and describe the processes taking place during pumping the fluid in the high-pressure part of the pump with a hypocycloidal drive, it is necessary to characterize the compressibility of the fuel [1]. This case is complex because the fluid is understood here as gas and liquid, being separate media, and the solution (being the liquid phase) resulting from their combination. In order to create a solution of the fuel with $\mathrm{CO}_{2}$ or other gas, it is necessary to supply work to the system in the form of pressure. In the pump, this is achieved by the movement of the piston allowing the gas and liquid to be compressed, thereby dissolving the gas in the liquid fuel [25]. The gas and the liquid initially remain separate media before the delivery stroke, this is due to the way carbon dioxide and fuel are supplied separately to the delivery chamber during the intake stroke. The movement of the piston towards the top position causes the gas to compress isothermally. This character of the process was assumed because the work is performed by the forces of the piston drive, while the temperature is kept at a constant level because the gas gives off heat to the environment. A new 
cooling system is used in the pump, therefore, compression is assumed by an isothermal process, and in the $\mathrm{p}-\mathrm{V}$ diagram, the isotherm assumes the function of a hyperbola from the equation of state:

$$
\mathrm{p}=\frac{\text { const }}{\mathrm{V}}=\frac{\mathrm{nRT}}{\mathrm{V}}
$$

The remaining volume of the delivery section occupied by the solution is reduced, which is explained by the compressibility of the liquid with general characteristics in a simple form. Combining the two graphs obtained, it can be concluded that the gas compression process turns into an asymptotic compressibility function of the resulting solution. On the other hand, the transition point from one function to another is the end point of the process of dissolving gas in a liquid, and thus creating a solution. The process of liquid compression can be described by an index that characterizes it. The compressibility factor $\beta$ is defined as the degree of susceptibility of a fluid to volumetric deformation and pressure changes, disregarding the conditions under which measurements are made, i.e. changes in temperature or entropy:

$$
\beta=-\frac{1}{\mathrm{~V}} \frac{\mathrm{dV}}{\mathrm{dp}}
$$

The bulk modulus of the solution $\mathrm{B}$ is the reciprocal of the compressibility coefficient:

$$
\mathrm{B}=\frac{1}{\beta}
$$

Inserting into the previous equation, the bulk modulus of the solution is described as follows:

$$
B=-V \frac{d p}{d V}
$$

the sign "-" only defines the direction of volume changes under the influence of the acting pressure.

Another important parameter to consider in the desorption effect is the coefficient of solubility. The solubility of gases under normal atmospheric conditions is low, however, when two independent parameters of temperature and pressure change, the determination of the degree of gas solubility in the liquid turns out to be important. The quantity by which it is possible to determine the amount of gas dissolved in a liquid is the quantity q, meaning "the number of grams that is dissolved in $100 \mathrm{~g}$ of pure solvent at a given temperature, when the total pressure (partial pressure of saturated vapor above the liquid) at the absorption temperature is $760 \mathrm{~mm} \mathrm{Hg}$ " [21]. Using two interdependent processes occurring during the stroke of the pump piston; compressing fluids and dissolving a gas in a liquid; can physically describe the degree of solubility and its course. Thus, in the formula for the modulus of compressibility (5), it can be assumed that changes in volume $\mathrm{V}(\mathrm{p})$ are related to pressure changes [8]. According to this condition, the modulus of compressibility (6) can be written as follows:

$$
\frac{\mathrm{dV}}{\mathrm{V}}=-\frac{\mathrm{dp}}{\mathrm{B}}
$$

On the other hand, the modulus of compressibility depends on the changes in pressure $B(p)$ :

$$
B(p)=a_{0} \cdot p+b_{0}
$$

and

$$
\mathrm{B}(\mathrm{p})=\mathrm{a}_{\mathrm{r}} \cdot \mathrm{p}^{2}+\mathrm{b}_{\mathrm{r}} \cdot \mathrm{p}+\mathrm{c}_{\mathrm{r}}
$$

where the relationship (a) together with the coefficients a0 and $b_{0}$ relates to the compressibility of the liquid-diesel fuel, while equation (b) and the coefficients $a_{r}, b_{r}, c_{r}$ to the compressibility of the solution - diesel fuel with gas. The changes in the coefficients taken from the literature are presented in the curves in the diagram (Fig. 6).

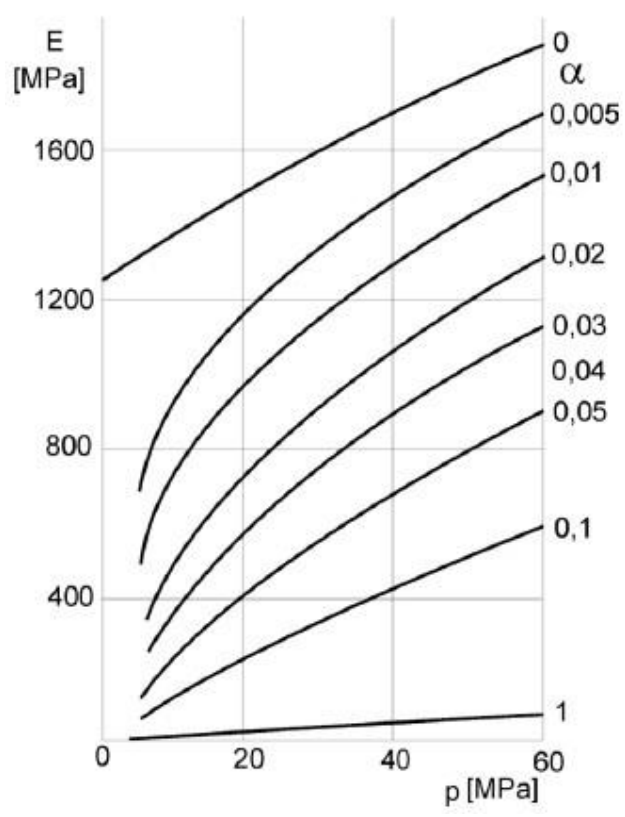

Fig. 6. The bulk modulus B of the mixture of diesel oil and gas, $\alpha-$ relative gas volume in the pumping chamber, $\mathrm{p}$ - pressure [4]

The course of the pressure-dependent gas solubility curve is similar to the course of the value of the solution compressibility modulus according to the formula (8). Thus, it was assumed that the pressure-dependent gas solubility coefficient in diesel fuel is described by the equation:

$$
q=a_{2} \cdot p^{2}+a_{1} \cdot p+a_{0}
$$

\section{Volumetric losses of the compression process}

A hypocycloidal pump designed to dissolve gas in a liquid has losses due to the operating characteristics and compression of these two fluids. All losses translate into the values of the torque obtained on the drive shaft and the power loading the engine that drives the pump. The power that the pump draws from the source (electric or combustion engine) is the sum of the individual values: power output of the pump $\mathrm{P}_{\mathrm{Pu}}$, the power of pressure losses $\Delta \mathrm{P}_{\mathrm{Pp}}$, the power of volumetric losses of leaks $\Delta \mathrm{P}_{\mathrm{Pvl}}$, the power of mechanical losses $\Delta \mathrm{P}_{\mathrm{Pm}}$ and the power of volumetric compression losses of the fluid $\Delta \mathrm{P}_{\mathrm{Pv}}$, which are described by the equation [20]:

$$
\Delta \mathrm{P}_{\mathrm{Pc}}=\mathrm{P}_{\mathrm{Pu}}+\Delta \mathrm{P}_{\mathrm{Pp}}+\Delta \mathrm{P}_{\mathrm{Pvl}}+\Delta \mathrm{P}_{\mathrm{Pm}}+\Delta \mathrm{P}_{\mathrm{Pvc}}
$$

In the above formula, it can be seen that in order to describe the effect of pumping a liquid and a gas, both fluids being compressed to a certain extent, it is necessary to characterize the volumetric compression losses of the fluids 
- they result from the compressibility of the liquid and gas and the solution formed from the dissolved gas in this liquid. On the other hand, gas dissolved in diesel fuel does not change its compressibility. Such losses are closely related to compression and do not depend on the mechanical design of the pump. They are part of the results of actual measurements of volumetric leakage losses and should be taken into account even though their values are small.

The starting point for assessing the power of volumetric losses is the description of the pump efficiency losses $\mathrm{q}_{\mathrm{Pvc}}$, which reduce the active volume of the fuel pumped during one revolution of the shaft (here full piston stroke) in relation to the theoretical volume $\mathrm{q}_{\mathrm{Pt}}-$ of the entire section. The reason for this process is the compressibility of the liquid.

Using the simulation of the dynamic operation of the unit, the pump efficiency losses were determined using the theoretical method, so the following input parameters were assumed: pressure generated by the pump 1500 bar, fuel pressure from the low-pressure side $8 \mathrm{bar}$, rotational speed of the drive shaft $1500 \mathrm{rpm}$ and fuel filling $75 \%$. To determine the volumetric losses of the pump efficiency per one revolution of the drive shaft, which are the result of the compressibility of oil and gas, an analysis was used in [7]. The compressibility modulus of diesel oil is characterized by the relations (4) and (5) and, assuming a low compressibility of diesel oil, similar to that of hydraulic oils (Fig. 6), it can be described by the dependence of changes in pressure and temperature

$$
\mathrm{B}=\mathrm{B}_{\mathrm{Pp}_{1}=0.8 \mathrm{MPa} ; \mathrm{T}=20^{\circ} \mathrm{C}}\left(1+\mathrm{a}_{\mathrm{p}} \Delta \mathrm{P}_{\mathrm{pi}}+\mathrm{a}_{\mathrm{T}} \Delta \mathrm{T}\right)
$$

After the gas was sucked in and the fuel was supplied, the pressure in the pumping chamber was assumed as $\mathrm{p}_{\mathrm{p} 1}=$ $0.8 \mathrm{MPa}$ and that the process took place at a temperature of $\mathrm{T}=20^{\circ} \mathrm{C}$. According to [3] coefficient of increase B with increase in pressure $\mathrm{a}_{\mathrm{p}}=0.005 / 1 \mathrm{MPa}$ and decrease coefficient $\mathrm{B}$ with increase in temperature $\mathrm{a}_{\mathrm{T}}=-0.005 / 1^{\circ} \mathrm{C}$. The initial value of the bulk modulus was also assumed from the diagram (Fig. 6) as:

$$
\mathrm{B}_{\mathrm{Pp}_{1}=0.8 \mathrm{MPa} ; \mathrm{T}=20^{\circ} \mathrm{C}}=1300 \mathrm{MPa}
$$

However, in further analysis, a own coefficient was proposed $\varphi=V_{a} / V_{0}$. This coefficient determines the ratio of the gas volume $V_{a}$ in the delivery section to the fuel volume $V_{o}$ contained in it when the section is filled. This is due to the fact that the gas volume cannot be neglected here in general in the release concept (14). However, the total volume of the section is: $V_{0}=V_{a}+V_{0}$. The volume of diesel and gas is reduced by the difference $\Delta \mathrm{V}$ under the pressure increase $\Delta \mathrm{p}_{\mathrm{p}}$, which gives the following equation [7]:

$$
\Delta \mathrm{V}=\Delta \mathrm{V}_{\mathrm{o}}+\Delta \mathrm{V}_{\mathrm{a}}=\frac{\mathrm{V}_{\mathrm{o}}}{\mathrm{B}} \Delta \mathrm{p}_{\mathrm{pi}}+\frac{\mathrm{V}_{\mathrm{a}}}{\mathrm{p}_{\mathrm{p} 1}+\Delta \mathrm{p}_{\mathrm{pi}}} \Delta \mathrm{p}_{\mathrm{pi}}
$$

Our own steps have been followed since:

$$
\Delta \mathrm{V} \neq \Delta \mathrm{V}_{0}
$$

this:

$$
\Delta V=V_{0} \Delta p_{p i}\left(\frac{1}{B}+\frac{\frac{V_{a}}{V_{0}}}{p_{p 1+\Delta p_{p i}}}\right)
$$

$$
\frac{\Delta \mathrm{V}}{\Delta \mathrm{p}_{\mathrm{pi}}}=\mathrm{V}_{0}\left(\frac{1}{\mathrm{~B}}+\frac{\frac{\mathrm{va}_{\mathrm{a}}}{\mathrm{V}_{0}}}{\mathrm{p}_{\mathrm{p} 1}+\Delta \mathrm{p}_{\mathrm{p} 1}}\right)
$$

From the dependencies (4) and (5) and the assumption that B 'replacement module - defines the solution:

$$
\begin{gathered}
\Delta \mathrm{V}=-\beta^{\prime} \mathrm{V}_{0} \Delta \mathrm{P}_{\mathrm{pi}} \\
\frac{\Delta \mathrm{V}}{\Delta \mathrm{P}_{\mathrm{pi}}}=\frac{1}{\mathrm{~B}^{\prime}} \mathrm{V}_{0}
\end{gathered}
$$

By combining two equations and further simplifying:

$$
\begin{gathered}
\frac{1}{\mathrm{~B}^{\prime}} \mathrm{V}_{0}=\mathrm{V}_{\mathrm{o}}\left(\frac{1}{\mathrm{~B}}+\frac{\frac{\mathrm{V}_{\mathrm{a}}}{\mathrm{V}_{\mathrm{o}}}}{\mathrm{p}_{\mathrm{p} 1}+\Delta \mathrm{p}_{\mathrm{pi}}}\right) \\
\frac{1}{\mathrm{~B} \prime}=\frac{\mathrm{V}_{0}}{\mathrm{~V}_{\mathrm{o}}}\left(\frac{1}{\mathrm{~B}}+\frac{\frac{\mathrm{V}_{\mathrm{a}}}{\mathrm{V}_{\mathrm{o}}}}{\mathrm{p}_{\mathrm{p} 1}+\Delta \mathrm{p}_{\mathrm{pi}}}\right) \\
\frac{1}{\mathrm{~B} \prime}=\frac{\mathrm{V}_{0}}{\mathrm{~V}_{\mathrm{o}}+\mathrm{V}_{\mathrm{a}}}\left(\frac{1}{\mathrm{~B}}+\frac{\frac{\mathrm{V}_{\mathrm{a}}}{\mathrm{V}_{\mathrm{o}}}}{\mathrm{p}_{\mathrm{p} 1}+\Delta \mathrm{p}_{\mathrm{pi}}}\right) \\
\frac{1}{\mathrm{~B} \prime}=\frac{1}{\frac{V_{\mathrm{o}}+\mathrm{V}_{\mathrm{a}}}{\mathrm{V}_{\mathrm{o}}}}\left(\frac{1}{\mathrm{~B}}+\frac{\frac{\mathrm{V}_{\mathrm{a}}}{\mathrm{V}_{\mathrm{o}}}}{\mathrm{p}_{\mathrm{p} 1}+\Delta \mathrm{p}_{\mathrm{pi}}}\right) \\
\frac{1}{\mathrm{~B} \prime}=\frac{1}{1+\frac{\mathrm{V}_{\mathrm{a}}}{\mathrm{V}_{\mathrm{o}}}}\left(\frac{1}{\mathrm{~B}}+\frac{\frac{\mathrm{V}_{\mathrm{a}}}{\mathrm{V}_{\mathrm{o}}}}{\mathrm{p}_{\mathrm{p} 1}+\Delta \mathrm{p}_{\mathrm{pi}}}\right)
\end{gathered}
$$

By introducing a new factor:

$$
\varphi=\frac{\mathrm{v}_{\mathrm{a}}}{\mathrm{v}_{\mathrm{o}}}
$$

Giving finally:

$$
\frac{1}{\mathrm{~B} \prime}=\frac{1}{1+\varphi}\left(\frac{1}{\mathrm{~B}}+\frac{\varphi}{\mathrm{p}_{\mathrm{p} 1}+\Delta \mathrm{p}_{\mathrm{pi}}}\right)
$$

The resulting dependence of the compressibility coefficient can be made dependent on the initial conditions for which the bulk modulus (11) and (12) were defined:

$\frac{1}{\mathrm{~B}^{\prime}}=\frac{1}{1+\varphi}\left(\frac{1}{\mathrm{~B}_{\mathrm{Pp}_{1}=0.8 \mathrm{MPa} ; \mathrm{T}=20^{\circ} \mathrm{C}}\left(1+\mathrm{ap}_{\mathrm{p}} \Delta \mathrm{p}_{\mathrm{pi}}+\mathrm{a} \mathrm{T} \Delta \mathrm{T}\right)}+\frac{\varphi}{\mathrm{p}_{\mathrm{p} 1}+\Delta \mathrm{p}_{\mathrm{pi}}}\right)$ (26)

To sum up, the compressibility modulus of diesel oil and gas was made dependent on the pressure indicated in the piston pump and the temperature of the fuel itself. However, it is somewhat inaccurate, because the equation has a slight error in not taking into account the dissolution of the gas, i.e. reducing its volume in favor of the liquid. Returning to the previously defined parameters for a pump with a hypocycloidal drive, determining the efficiency losses resulting from the type of the pumped liquid (differences in compressibility of fluids) may give greater possibilities in terms of precise metering of injected fuel doses. On the basis of the derived formula (26), the curves of the bulk modulus B ' for different volume ratios $\varphi$ gas - diesel oil as a dependence on the indicated pump pressure $\Delta \mathrm{p}_{\mathrm{pi}}$ were determined for this case (Fig. 7).

The line $\varphi=0$ is the course of the diesel fuel compressibility modulus without gas, i.e. with $100 \%$ full fuel filling. The line $\varphi=0.33$ means that it is $75 \%$ filled with fuel, and $25 \%$ is filled with exhaust gas. The fuel volume in the latter 
case is lower than at $\varphi=0$, thus the pump capacity is limited in relation to the fuel. The difference lies in the degree to which the working chamber is filled with fuel. The bulk modulus curves in the diagram (Fig. 8) have a certain difference $\Delta \mathrm{x}$ in the course for each indicated pressure. This is due to the greate compressibility $\left(\beta=1 / \mathrm{B}^{\prime}\right)$ of the mixture at $\varphi=0.33$, i.e. the gas itself than diesel fuel without flue gas $(\varphi=0)$. The vertical red line (exemplary) specifies for the curve $\varphi=0.33$ the pressure at which exhaust gas is completely dissolved in diesel fuel. Up to this point, the graph follows the equation (26), which means the simultaneous compression of gas and liquid. Further, the equation takes the form for diesel fuel with gas $(\varphi=0.33)$ :

$$
\frac{1}{B^{\prime}}=\frac{1}{1+\varphi}\left(\frac{1}{\mathrm{BPp}_{2}=10 \mathrm{MPa} ; \mathrm{T}=20^{\circ} \mathrm{C}}+\frac{\varphi}{p_{p 1}+\Delta p_{p i}}\right)
$$

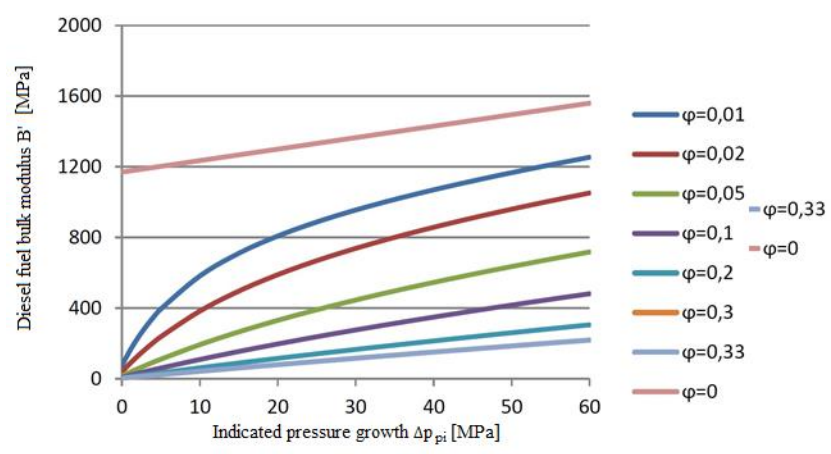

Fig.7. The bulk modulus B depends on the indicated pressure of the pump, where $\varphi=0$ means pure diesel oil, $\varphi>0$ means diesel fuel with gas in certain ratios, $\varphi=0.33$ determines the volume ratio for the example of a hypocycloidal pump

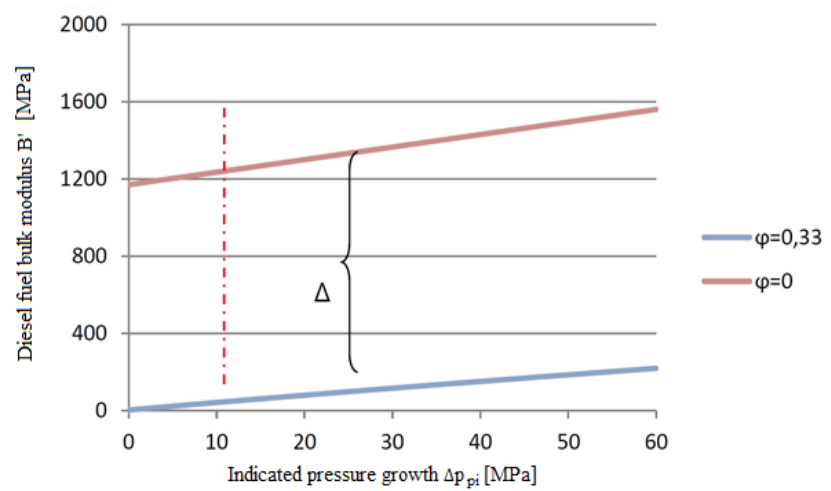

Fig. 8. The bulk modulus $B$ ' depends on the indicated pressure of the pump, where $\varphi=0$ means pure diesel fuel, $\varphi=0.33$ determines the ratio of the gas volume $V_{a}$ to $V_{0}$ for the simulation of a hypocycloidal pump

At the end point of dissolution $\left(\mathrm{V}_{\mathrm{a}}\right.$ to $\left.\mathrm{V}_{\mathrm{o}}\right)$ of the exhaust gas in diesel fuel, the denominator of the volumetric ratio $\mathrm{V}_{\mathrm{a}} / \mathrm{V}_{\mathrm{o}}=25 / 75$ tends to 100 , but does not reach it. This is due to the fact that the gas having greater compressibility dissolves, while at the same time it is compressed to a greater extent than the compression of the liquid. Thus, the volume of the solution does not reach the value equal to the volume of diesel fuel alone (when $\varphi=0$ ). It can be noticed that at the same point the gas volume $V_{a}$ approaches zero (dissolution of exhaust gases in the liquid), then $\varphi$ also reaches zero, so the equation simplifies to:

$$
\frac{1}{\mathrm{~B}^{\prime}}=\frac{1}{1+\varphi}\left(\frac{1}{\mathrm{~B}_{\mathrm{Pp}_{2}=10 \mathrm{MPa} ; \mathrm{T}=20^{\circ} \mathrm{C}}\left(1+\mathrm{a} \Delta \mathrm{p}_{\mathrm{pi}}+\mathrm{a}_{\mathrm{T}} \Delta \mathrm{T}\right)}+\frac{\varphi}{\mathrm{p}_{\mathrm{p} 1}+\Delta \mathrm{p}_{\mathrm{pi}}}\right)
$$

It is a definition of the compression of the solution, so the curve further increases slightly, which may be omitted in the following calculations. At the point where dissolution occurs, the initial volume of the fuel is equal to the volume of the solution due to the low compressibility of the liquid.

The next step is to determine the volume $\mathrm{q}_{\mathrm{Pvc}}$ losses according to the relationship [7]:

$$
\mathrm{q}_{\mathrm{P}_{\mathrm{vc}}}=\mathrm{q}_{\mathrm{Pt}}\left(\frac{1}{\mathrm{~B}^{\prime}}\right) \Delta \mathrm{p}_{\mathrm{pi}}\left[\mathrm{cm}^{3} / \mathrm{rev}\right]
$$

where $\mathrm{q}_{\mathrm{Pt}}$ is the theoretical working volume defined for one revolution of the shaft in $\left[\mathrm{cm}^{3} / \mathrm{rev}\right]$ according to:

$$
\mathrm{q}_{\mathrm{P}_{\mathrm{vc}}}=\frac{\pi \mathrm{d}^{2}}{4} \cdot \mathrm{h}=\frac{\pi 0.63^{2}}{4} \cdot 4=1.2462\left[\mathrm{~cm}^{3} / \mathrm{rev}\right]
$$

A graph (Fig. 9) of volumetric losses caused by compressibility was obtained.

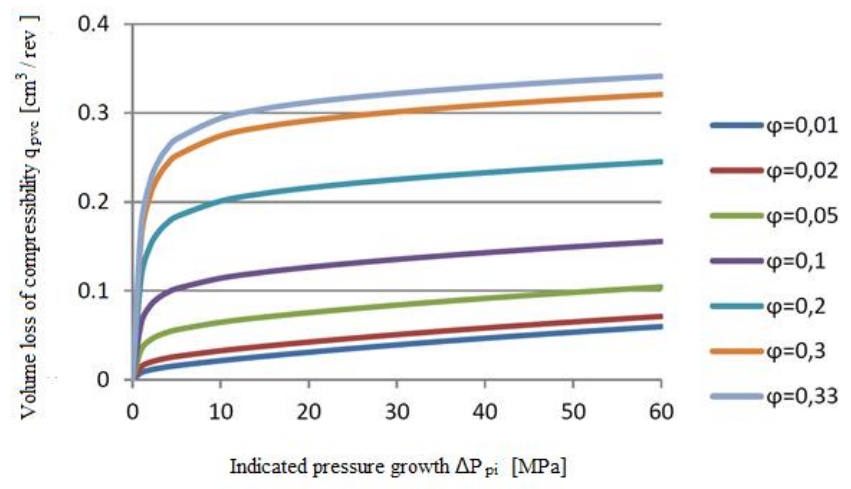

Fig. 9. Volumetric losses caused by compressibility depending on the indicated pressure of the pump, where $\varphi>0$ means diesel fuel with gas in certain ratios, $\varphi=0.33$ determines the volume ratio for the example of a hypocycloidal pump

On the other hand, the power of volumetric compressibility losses, calculated by the formula (30), takes the following form [20]:

$$
\Delta \mathrm{P}_{\mathrm{PvcPn}}=\mathrm{q}_{\mathrm{PvcPn}} \cdot \frac{\mathrm{P}_{\mathrm{n}}}{2} \cdot \mathrm{n}_{\mathrm{PPn}}=36.8 \mathrm{~W}
$$

where: $\mathrm{q}_{\mathrm{PvcPn}}-$ are volumetric compression losses where for $\varphi=0.33$ and $10 \mathrm{MPa}$ (in which complete dissolution occurs) are $0.300\left[\mathrm{~cm}^{3} / \mathrm{rev}\right], \mathrm{P}_{\mathrm{n}}-$ dissolution end pressure $10 \mathrm{MPa}, \mathrm{n}_{\mathrm{PPn}}$ - dissolution end pressure $10 \mathrm{MPa}$.

\section{Summarizing}

The authors of the study proposed to use the effect of gas desorption from solution with nucleation of gas bubbles. As empirically proven, this process has a significant impact on the engine's emissions. In addition, the use of relatively low injection pressures allows the mechanical stress relief of the high pressure pump components. The concept of dissolving exhaust gases in diesel fuel is realized by a sharp drop in thermodynamic potential, which results 
in a rapid release of gas from the solution. Thus, the described mechanism causes the fuel droplets to burst from the inside. It is therefore an additional factor supporting the existing atomization mechanism. The implementation of the process requires the creation of a new pump design, in which the dissolution of exhaust gases in diesel fuel will take place by means of a pressure section. The influence of the bulk modulus and the coefficient of solubility of the solution of diesel fuel and exhaust gas had to be analyzed. However, this article focuses on the volumetric losses of the compression process that take place in a hypocycloidal pump.

It was proved that the power of volumetric losses in compression of oil with dissolved gas for an indicated pressure of $10 \mathrm{MPa}$ and $\varphi=0.33$, i.e. $25 \%$ of exhaust gases in the delivery section, is $0.037 \mathrm{~kW}$. As calculated in the simulation, the total power consumed by the pump was 14.5 $\mathrm{kW}$. Thus, the power of volumetric losses resulting from compressibility is $0.25 \%$ of the power consumed by the pump. It follows that the increase in the volume of gas and its mass in the chamber causes greater losses of efficiency resulting from compressibility than losses of efficiency when the total volume is filled with fuel, i.e. at the time of full expenditure. This is a slight value, but determined only for the step of simultaneously compressing the liquid fuel and the gas (exhaust) until it dissolves. Further compressive losses of the liquid have higher values. The determination of these losses can be used to verify the value of the leakage losses.

\section{Bibliography}

[1] ARMAS, O., MARTINEZ-MARTINES, S., PACHECO, C. Alternative method of bulk modulus estimation of diesel fuels. Fuel. 2016, 167, 199-207.

https://doi.org/10.1016/j.fuel.2015.11.067

[2] BATTINO, R., CLEVER, H.L. The solubility of gases in liquids. Chemical Reviews. 1966, 66(4), 395-463. https://doi.org/10.1021/cr60242a003

[3] FAlCIGLIA, P.P., GIUSTRA, M.G., VAGLIASINDI, F.G.A. Low-temperature thermal desorption of diesel polluted soil: influence of temperature and soil texture on contaminant removal kinetics. Journal of Hazdous Materials. 2011, 185(1), 392-400.

https:/doi.org/10.1016/j.jhazmat.2010.09.046

[4] FALKOWSKI, H., HAUSER, G., JANISZEWSKI, T. et al. Układy wtryskowe silników wysokoprężnych. Wydawnictwo Komunikacji i Łaczności. Warszawa 1989.

[5] FREITAS, S.V.D., SEGOVIA, J.J., MARTIN, M.C. et al. Measurment and prediction of high-pressure viscosities of biodiesel fuels. Fuel. 2014, 122, 223-228.

https://doi.org/10.1016/j.fuel.2014.01.031

[6] GRISHINA, I.N., BASHKATOVA, S.T., KOLESNIKOV, I.M. et al. Thermodynamics of moisture dissolution in diesel fuel. Petroleum Chemistry. 2009, 49(6), 512-515. https://doi.org/10.1134/S0965544109060115

[7] KORALEWSKI, J. Wpływ lepkości i ściśliwości oleju na wyznaczanie strat objętościowych w pompie tłokowej o zmiennej wydajności. Centrum Mechanizacji Górnictwa „Komag”. Gliwice 2013.

[8] KOZAK, W. Kształtowanie parametrów wtrysku do silników o zapłonie samoczynnym. Wydawnictwo Politechniki Poznańskiej. Poznań 2008.

[9] KOZAK, W., BAJERLEIN, M., MARKOWSKI, J. The application of gas dissolved in fuel with a view to improve the mechanism of spraying. Combustion Engines. 2005, 120(1), 4-18. https://doi.org/10.19206/CE-117407

[10] KUDŹMA, Z., MAĆKIEWICZ, J. Badanie zjawiska kawitacji w pompach wyporowych. Pomiary Automatyka Robotyka. 2016, 20(1). http://dx.doi.org/10.14313/PAR_219/17

[11] KUKIEŁKA, Z., WOŹNIAK, D., WOŹNIAK, J. Wybrane aspekty zużycia kawitacyjnego w silnikach spalinowych. Autobusy. 2012, 5.

[12] LI, P.M., ZHANG, Y.T., LI, T.S. et al. Elimination of fuel pressure fluctuation and multi-injection fuel mass deviation of high pressure common-rail fuel injection system. Chinese Journal of Mechanical Engineering. 2015, 28(2), 294-306. https://doi.org/10.3901/CJME.2014.1216.180
[13] LILACH, Y., DANZIGER, I.M., ASSCHER, M. Second order isothermal desorption kinetics. Catalysis Letters. 2001, 76(1-2), 35-39. https://doi.org/10.1023/A:1016724025447

[14] MA, X., ABE, Y., KANEKO, A. et al. Study on dissolution process of liquid $\mathrm{CO}_{2}$ into water under high pressure condition for CCS. Energy Procedia. 2017, 114, 5430-5437. https://doi.org/10.1016/j.egypro.2017.03.1687

[15] MEEK, G., WILIAMS, R., THORNTON, D. et al. Ultra high pressure distributed pump common rail system. SAE Technical Paper 2014-01-1440. 2014. https://doi.org/10.4271/2014-01-1440

[16] MERKISZ, J., BAJERLEIN, M., KOZAK, W. Dissolving oxygen in diesel fuel as a way to make road transport more environmentally friendly. WIT Transactions on The Built Environment. 2008, 101, 325-334. https://doi.org/10.2495/UT080321

[17] MERKISZ, J., BAJERLEIN, M., KOZAK, W. et al. The influence of CNG dissolved in the diesel fuel on the combustion process and concentration of toxic compounds in exhaust gas. SAE Technical Paper 2008-01-1815. 2008. https://doi.org/10.4271/2008-01-1815

[18] NAGATA. K. State-of-art technologies for diesel common rail system. SAE Technical Paper 2004-28-0068. 2004. https://doi.org/10.4271/2004-28-0068

[19] OJEDEJI, D., PERRY, S., NIELSEN, J. et al. Experimental investigation of desorption kinetics of methane in diesel and internal olefin for enhanced well control. Greenhouse $\mathrm{Ga}$ ses-Science and Technology. 2020, 10(2), 364-379. https://doi.org/10.1002/ghg.1967

[20] PASZOTA, Z. Porównanie mocy strat energetycznych w pompie wyporowej o zmiennej wydajności, określonych bez uwzględnienia bądź z uwzględnieniem mocy ściskania oleju hydraulicznego. Napędy i Sterowanie. 2014, 11, 132-143.

[21] PIGOŃ, K., RÓZEWICZ, Z. Chemia fizyczna. Państwowe Wydawnictwo Naukowe. Warszawa 1980.

[22] WLOKA, J., PFLAUM, S., WECHTEISTER, G. Potential and challenges of a 3000 bar common-rail injection system considering engine behavior and emission level. SAE International Journal of Engines. 2010, 3(1), 801-813. https://doi.org/10.4271/2010-01-1131

[23] YE, P., SUN, C., LAPUERTA, M. et al. Impact of rail pressure and biodiesel fueling on the particulate morphology and soot nanostructures from a common-rail turbocharged direct injection diesel engine. International Journal of Engine Research. 2014, 17(2), 193-208. https://doi.org/10.1177/1468087414564229 
[24] ZHANG, J.H., LI, W.D., LIN, J.W. et al. Failure analysis of a high-pressure fuel pipe of engine. Engineering Failure Analysis. 2019, 103, 70-81.

https://doi.org/10.1016/j.engfailanal.2019.04.040

[25] ZHAO, J.H., GREKHOV, L., MA, X.Z. et al. Specific features of diesel fuel supply under ultra-high pressure. Applied Thermal Engineering. 2020, 179, 115699.

https://doi.org/10.1016/j.applthermaleng.2020.115699

Maciej Bajerlein, DSc., DEng. - Faculty of Civil and Transport Engineering, Poznan University of Technology.

e-mail: maciej.bajerlein@put.poznan.pl

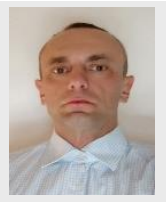

Wojciech Karpiuk, DEng. - Faculty of Civil and Transport Engineering, Poznan University of Technology.

e-mail: wojciech.karpiuk@put.poznan.pl
[26] ZHU, J., KUTI, O.A., NISHIDA, K. An investigation of the effects of fuel injection pressure, ambient gas density and nozzle hole diameter on surrounding gas flow of a single diesel spray by the laser-induced fluorescence-particle image velocimetry technique. International Journal of Engine Research. 2012, 14(6), 630-645.

https://doi.org/10.1177/1468087412458778

Prof. Marek Idzior, DSc., DEng. - Faculty of Civil and Transport Engineering, Poznan University of Technology.

e-mail:marek.idzior@put.poznan.pl

Rafał Smolec, MEng. - Faculty of Civil and Transport Engineering, Poznan University of Technology.

e-mail: rafal.smolec@put.poznan.pl 